ISSN 1518-3483

Licenciado sob uma Licença Creative Commons

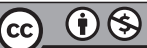

\title{
Prática de Ensino e Estágios Supervisionados: da observação de modelos à aprendizagem da docência
}

\author{
Teaching Practice and Supervised Training: \\ the observation of models until \\ teaching-learning process
}

\section{Magali Aparecida Silvestre}

Professora associada, Universidade Federal de São Paulo (UNIFESP), Guarulhos, SP - Brasil, e-mail: magali.silvestre@unifesp.br

\section{Resumo}

Este artigo apresenta, de forma sumária, como as políticas de formação de professores se delinearam ao longo da história da educação brasileira e, nessa trajetória, de que modo as disciplinas Práticas de Ensino e Estágios Supervisionados foram concebidas e incorporadas aos cursos de formação inicial. Tomando-se por base as práticas de formação de professores, anteriores ao surgimento da primeira Escola Normal brasileira, no século XIX, e os 
modelos que se seguiram até o século XXI, culminando com a transformação do curso de Pedagogia em licenciatura, o texto ressalta as marcas das diversas concepções que caracterizaram essas duas disciplinas e as configuraram em espaços especialmente adequados para viabilizar a aprendizagem da docência.

Palavras-chave: Estágio Supervisionado. Prática de Ensino. Formação inicial de professores.

\section{Abstract}

This article presents in summary form, how policies for teacher education were outlined throughout the history of Brazilian education, in it's trajectory, in which way the Practice Teaching disciplines and Supervised Training have been designed and incorporated into the initial training courses. Taking as a basis the practices of teacher training prior to the onset of the first Normal School in Brazil in the nineteenth century and the models that followed until the XXI century, culminating with the transformation of the pedagogy course in degree, the text highlights the marks of several concepts that have characterized these two disciplines and configured in spaces specifically adapted to enable the learning of teaching.

Keywords: Supervised Training. Teaching Practice. Initial teacher training formation.

\section{Introdução}

O professor, em seu processo de formação, inicial ou continuada, constitui-se em uma dada realidade social, fruto de um longo processo histórico, traduzido nas relações sociais nas quais ele está envolvido; processo que vai se transformando de acordo com as exigências e demandas econômicas, sociais e políticas. Ora, ao mesmo tempo determinado e determinante, esse profissional deve reconhecer o nível de responsabilidade que possui sobre o processo e resultados do complexo universo da educação formal.

Não pode ser totalmente responsabilizado, como vem acontecendo, mas deve se corresponsabilizar pelo fracasso/sucesso da escola, 
porque o trabalho docente bem feito é condição básica para a busca de melhoria da qualidade.

É nesse contexto que compreendemos a importância e os limites da formação inicial de professores, como um tempo em que se organizam as bases da docência, e é nesse mesmo contexto que enxergamos a possibilidade de promover a formação de pessoas que assumam seu ofício com o compromisso de mudança.

Nesse sentido, como formadora de formadores, nos indagamos sobre qual o lugar que os estágios curriculares obrigatórios, que preveem práticas de atuação dos alunos, ocupam no projeto de um curso de formação inicial de professores e sobre como esses estágios contribuem decisivamente para a constituição da profissionalização docente.

A defesa da importância do estágio curricular obrigatório, em cursos de formação de professores, relacionado à ideia de "contato com a prática", "iniciação ao ofício", "aprender pela prática”, "unir teoria e prática”, não só naturalizou sua existência nos processos formativos, como também esvaziou o conteúdo dessa obrigatoriedade. Afinal, qual o impacto dos estágios e práticas de ensino na aprendizagem da docência?

Nessa direção, reconhecemos que investigar essa temática poderia oferecer elementos que enriqueceriam o debate. Foi com essa perspectiva que desenvolvemos um estudo que teve como foco de investigação as práticas supervisionadas desencadeadas nos cursos de formação por meio dos estágios curriculares. Apoiado no referencial teórico metodológico sócio-histórico, seu objeto central de análise consistiu na apreensão dos significados e sentidos de uma aluna de um curso de Pedagogia sobre as práticas de ensino desenvolvidas em escolas-campo durante o período dos estágios curriculares obrigatórios. A pesquisa apontou os limites de uma prática docente que se esvaziou no espontaneísmo, por não estar amparada por um conhecimento profissional específico e consistente.

No entanto, para desenvolvermos o estudo precisávamos conhecer a rede de significações, construídas ao longo da história, sobre formação de professores e aprendizagem da docência. Para tanto, resolvemos percorrer a história da educação brasileira e desvelar como as políticas de 
formação de professores se delinearam ao longo do tempo e, nessa trajetória, de que modo as disciplinas Práticas de Ensino e Estágios Supervisionados foram concebidas e incorporadas aos cursos de formação inicial.

Escolhemos esse caminho, principalmente, por acreditar que nos revelaria as marcas das diversas concepções que caracterizaram essas duas disciplinas e as configuraram em espaços especialmente adequados para viabilizar a aprendizagem da docência, facilitando nossa compreensão sobre alguns significados e sentidos constituídos sobre a docência que ainda prevalecem neste século.

Portanto, neste artigo apresentamos, de forma sumária, uma parte do resultado que compõe a totalidade do estudo mencionado anteriormente e que foi delineada por meio de uma revisão bibliográfica sobre o tema.

Nessa medida, podemos anunciar com segurança que os desafios e a falta de qualidade na formação inicial de professores das séries iniciais do ensino fundamental sempre estiveram subjugados à descontinuidade das propostas do Estado brasileiro para a educação escolar, em especial para aquela que se dá em espaço público.

Decorrente desse fato, o currículo das Escolas Normais, que durante mais de cem anos foi o único espaço institucionalizado de formação de professores, sempre foi muito similar ao currículo da escola primária. Isso indica que as práticas de formação possuem em sua raiz a ideia de que o domínio dos conteúdos específicos de cada área do conhecimento - saberes disciplinares, no entendimento de Tardif (2002), seria a primeira condição para exercer o magistério, e que o fazer, a ação de ensinar, se aprendia pela própria prática, principalmente por meio da observação e do modelo.

Soma-se a isso outro indicador importante que demarca as mudanças constantes dos currículos e a presença contínua de mais de uma instância de formação ao longo dos diferentes períodos históricos. Buscando muito mais o baixo custo do que a excelência, do Império à República, a formação de professores se deu de forma alternada entre o método mútuo das Escolas das Primeiras Letras e os exercícios práticos da Escola Normal, acomodando, nesse tempo, a figura do professor adjunto. Fato que se repetiu nas décadas de 80 e 90, com a coexistência 
de três instâncias de formação: os cursos de Pedagogia, as Habilitações Específicas para o Magistério e os CEFAMs.

Finalmente, quando no início deste século a formação inicial se estabelece no ensino superior, com a transformação do curso de Pedagogia em licenciatura, assistimos a um retorno dos princípios escolanovistas pela exaltação daquilo que se denominou epistemologia da prática. Concepção que, em um caminho inverso ao traçado pela tradição apontada anteriormente, sobrepõe a prática em detrimento da teoria, insiste na dicotomia - inexistente - dessa relação e acaba ressaltando uma visão fragmentada do fenômeno educativo.

Dessa forma, conhecer o traçado histórico das disciplinas Prática de Ensino e Estágios Supervisionados possibilita argumentarmos sobre como a formação de professores foi adiante ao longo dos anos, demarcando tentativas de mudanças, mas ainda não alcançou a qualidade desejada.

\section{Exercícios práticos como campo de aprendizagem da docência}

Nomeados em 1772 por meio de uma lei que tinha como objeto a reforma dos estudos menores referentes às primeiras letras ${ }^{1}$, os primeiros professores leigos selecionados para exercerem a docência no Brasil chegaram de Portugal em número de 43, 16 deles responsáveis pelas aulas régias $^{2}$ de leitura, escrita e contagem (SAVIANI, 2007). Eles representavam a extensão das reformas pombalinas ${ }^{3}$ neste continente.

Desde então, séculos XVII e XVIII, o professor era selecionado muito mais por seus predicados pessoais do que pelos profissionais, e controlado por representantes do governo, com vistas à garantia da

1 O que corresponderia atualmente às séries iniciais do ensino fundamental.

2 As aulas régias eram o modelo de instrução pública que servia aos fins do Estado, em substituição às classes e escolas jesuíticas, que funcionavam em favor dos interesses da Igreja.

3 Reforma implantada, em 1759, pelo ministro português Marquês de Pombal, que, influenciado pelas ideias iluministas, entre outras coisas, fechou os colégios jesuítas e introduziu as aulas régias, a serem mantidas pela Coroa e não mais pela Igreja. 
propagação das ideias políticas vigentes. Mesmo sendo-lhe concedido o privilégio de nobre, trabalhava em condições precárias e era mal remunerado. Nenhum professor poderia lecionar sem aprovação e licença, por isso escolhido por "rigoroso exame feito por comissários delegados pelo Diretor Geral", sua aprovação dependia "dos requisitos de bons e provados costumes e de ciência e prudência” (SAVIANI, 2007, p. 84).

Se, por um lado, esse processo de estatização, em decorrência da secularização do magistério - passagem do domínio religioso para o regime leigo - significou uma possibilidade de constituição da profissão; por outro, a preocupação com a formação desse "novo" profissional só entrou em cena quase meio século mais tarde, com o surgimento das primeiras Escolas Normais: em 1835, na província do Rio de Janeiro, e em 1846, em São Paulo.

Nascida na sociedade imperial, sob a égide dos ideários liberais de extensão do ensino primário a todas as camadas da população, àquelas que eram livres, é importante ressaltar (ALMEIDA, 1993; TANURI, 2000), a Escola Normal surge em decorrência da necessidade de preparar o maior número de professores para atender às necessidades de expansão da "escola para todos", freqüentada, basicamente, pela classe média emergente da época.

Todavia, vários foram os fatores que colaboraram com uma trajetória marcada por processos de criação e extinção: era onerosa; ineficiente quanto à qualidade; poucos alunos se formavam; havia desinteresse da população pela profissão docente, como consequência do pouco atrativo financeiro e pouco reconhecimento de que gozavam os professores (SAVIANI, 2007; TANURI, 2000).

Contudo, a ausência de compreensão acerca da necessidade de formação específica para a docência é que punha em xeque a sua sobrevivência. À época, o currículo da Escola Normal era baseado na ideia de que o professor deveria conhecer um pouco mais profundamente aquilo que ia ensinar, ou, em outras palavras, dominar os conteúdos da Gramática e da Aritmética conferia-lhe competência para ensiná-los. 
Por esse motivo, as Escolas de Primeiras Letras, nas quais o método mútuo foi adotado, concorriam com as Escolas Normais. Por um custo bem menor e o entendimento de que a docência era aprendida na prática, esse método, que se tornou oficial em 1827, objetivava ensinar aos alunos as primeiras letras, como: ler, escrever e as quatro operações, além de preparar, para o domínio do método, aqueles que se saíam melhor, transformando-os em auxiliares do professor (SAVIANI, 2007; TANURI, 2000).

Muito embora o objetivo principal do método mútuo não tenha sido a "formação de professores", e sim instruir o maior número de pessoas a um baixo custo, Tanuri (2000, p. 63) ressalta que "foi realmente a primeira forma de preparação de professores, forma exclusivamente prática, sem qualquer base teórica [...]".

A ausência de uma base teórica na preparação dos professores também persistiu nos currículos das Escolas Normais. Almeida (1993) relata que a disciplina Métodos e Processos de Ensino, única disciplina pedagógica que compunha o currículo da Escola Normal de São Paulo, em 1846, foi extinta na mudança curricular que ocorreu no ano de 1864, permanecendo somente uma "recomendação" em seu regulamento, para que os exercícios práticos de ensino fossem realizados nas escolas primárias da capital.

Entre a luta pela sobrevivência da Escola Normal em algumas províncias, em meio às críticas constantes que sofria e o insucesso das Escolas de Primeiras Letras, principalmente atribuído à falta de instalações adequadas e à ineficácia do método mútuo, a instrução pública brasileira ia muito mal (SAVIANI, 2007; TANURI, 2000).

A avaliação de que a Escola Normal era pouco eficiente e muito cara, aliada ao entendimento de um ensino estritamente ligado à prática (SAVIANI, 2007), fez com que a figura do professor adjunto aparecesse em cena. Sistema de inspiração austríaca e holandesa (TANURI, 2000), já adotado desde 1849 pela província do Rio de Janeiro, foi ratificado em 1854 pela aprovação do Regulamento para a Reforma do Ensino Primário e Secundário do Município da Corte. 
Acreditando-se que a formação desses professores adjuntos deveria ocorrer na prática, ela se dava pela atuação de alunos como auxiliares de um professor público em exercício. Aqueles que se destacassem seriam nomeados adjuntos a partir de escolha pelo governo. Após três anos como adjunto - "triênio de habilitação" -, aperfeiçoando-se nas matérias e práticas de ensino, poderiam ser nomeados professores substitutos ou até mesmo professores públicos, desde que tivessem completado 18 anos e demonstrassem desempenho satisfatório (SAVIANI, 2007; TANURI, 2000).

Os desdobramentos do regulamento de 1854 permitem-nos considerar que o insucesso da Escola Normal não se deu apenas pelos elevados custos da proposta, ou pela falta de interesse da população em exercer o magistério, mas, principalmente, pelo entendimento que se tinha de como se aprendia a ser professor e qual o grau de importância atribuído pelos governantes ao processo de formação.

Contudo, mesmo fora de um modelo institucionalizado de formação, a figura do professor adjunto introduz, ao menos, a ideia de que, para ser professor, não basta "versar" sobre as matérias do ensino elementar, mas é necessário, também, aprender a forma de ensinar, que, nesse caso, se dava pelo exercício da prática.

Nessa conjuntura, Tanuri (2000) relata que a Escola Normal só voltou a ser pensada como principal instância de formação de professores na fase final do Império. Em meio às transformações de ordem ideológica, política e social, baseadas no discurso liberal iluminista, o setor educacional ganha relevo quando se dissemina a ideia de que a educação era indispensável ao desenvolvimento social e econômico do País.

Rompendo com o Regulamento de 1854, um novo Decreto, datado de 1879, que previa a reforma do ensino primário, secundário e superior na Corte, dispõe sobre o funcionamento das Escolas Normais, "fixando seu currículo, a nomeação de docentes, o órgão dirigente e a remuneração dos funcionários” (SAVIANI, 2007, p. 137).

Assim, as principais mudanças da Escola Normal dizem respeito à sua duração, que passou de dois para três anos, a existência de um currículo mais amplo e distinto para homens e mulheres e a introdução de disciplinas 
denominadas Pedagogia e Prática de Ensino Primário em Geral e Prática do Ensino Intuitivo ou Lição de Coisas ${ }^{4}$ (SAVIANI, 2007; TANURI, 2000).

Todavia, os exercícios práticos que constavam no currículo formalmente, em 1874, nas disciplinas Metódica e Pedagogia com Exercícios Práticos deixaram de existir formalmente, ainda que continuassem sendo realizados nas escolas primárias (ALMEIDA, 1993).

Foi somente em 1890, por meio da reforma de Caetano de Campos, já no novo governo republicano, que a Escola Normal ganhou novos rumos e o ideal de formação prática se alterou. A partir do pensamento pedagógico de Rangel Pestana, Caetano de Campos "implantou uma reforma baseada nos princípios da escola pública universal, gratuita, obrigatória e laica, colocando a formação do professor como fator fundamental para toda reforma de ensino" (ALMEIDA, 1993, p. 23).

Para tanto, foi instalada a Escola-Modelo Superior anexa à Escola Normal de São Paulo, caracterizada como um espaço destinado aos normalistas, para exercitar o que aprendiam na prática, fato que conferiu novo estatuto à formação.

Calcadas no método intuitivo ${ }^{5}$ de Pestalozzi, as Escolas-Modelo, que mais tarde se transformaram em Grupos Escolares, representaram um avanço na qualidade da formação de professores, pois, elevadas à condição de "setor de prática de ensino", permitiram a sistematização da Prática de Ensino como disciplina autônoma, detentora de metodologia própria, conferindo-lhe muita importância (ALMEIDA, 1993, p. 27).

Almeida (1993) relata que, no interior da Escola-Modelo, a Prática de Ensino era desenvolvida por meio do trabalho do aluno-mestre com as classes do primário, devidamente orientado por um professor, que era o encarregado de sua formação prática. Todavia, propunha-se uma Prática de

" Correspondia ao componente curricular da escola primária denominado "noções de coisas". Tratava-se do ensino de princípios de lavoura e horticultura; caligrafia e desenho linear; trabalho de agulhas para as meninas, prática manual de ofícios para os meninos, entre outros (TANURI, 2000).

${ }^{5}$ Método amplamente divulgado na Europa, dava muita importância à intuição, à observação e à experiência, por meio dos sentidos. 
Ensino reduzida à cópia do trabalho de outro professor, tendo a observação papel determinante nesse procedimento, caracterizando-se muito mais como um treinamento de técnicas do que como formação profissional.

Em que pese a existência de uma concepção de formação ainda pautada na observação e treinamento, portanto, em uma aprendizagem que ocorre "de fora para dentro", por meio dos sentidos - por isso observação e experimentação são a linha mestra -, a história nos leva a considerar que a integração entre as duas instâncias de formação - Escola Normal e Escola Modelo - representou uma conquista significativa e que só foi possível porque legitimada pelas políticas públicas existentes na época.

Nesta trajetória, a Escola Normal vai se consolidando como instituição formadora, mesmo passando por várias mudanças. Em 1892, o regulamento da Escola Normal previa, no primeiro ano do curso, o ensino da disciplina Pedagogia e Direção das Escolas, única disciplina responsável pela formação pedagógica, não apresentando formalmente os exercícios práticos que eram realizados nas Escolas-Modelo. Dois anos mais tarde, o curso é desdobrado em quatro anos; a disciplina Pedagogia e Direção das Escolas passa a ser ministrada no último ano, e os exercícios práticos, agora formalmente inseridos no currículo, passam a ser realizados no terceiro e quarto anos do curso (ALMEIDA, 1993; TANURI, 2000).

Nesse sentido, eleva-se o grau de importância atribuído à prática de ensino e os métodos e processos passam a ser considerados indispensáveis na formação dos professores (TANURI, 2000).

Em 1911, o País passou a manter dois tipos de escolas de formação oficializadas, passando a ser chamadas de Escolas Normais Primárias e Escolas Normais Secundárias. As primeiras ganharam em seu currículo a disciplina Pedagogia, ministrada no segundo e terceiro anos e Pedagogia e Educação Cívica, no quarto ano. As segundas receberam a disciplina Psychologia Experimental, no primeiro e segundo anos; e Methodos e Processos de Ensino, Crítica Pedagógica e Exercícios de Ensino, no terceiro e quarto anos (ALMEIDA, 1993).

Esse dualismo, explica Tanuri (2000), ratificado pela Lei Orgânica do Ensino Normal, de 1946, só foi extinto, na maioria dos Estados, com 
a Lei n. 5.692/71 (BRASIL, 1971), mais de sessenta anos depois, sendo o Estado de São Paulo uma exceção que sempre manteve um tipo único de ensino voltado para a formação de professores.

Apesar desse dualismo e das constantes alterações sofridas, principalmente nos currículos da Escola Normal, nota-se um avanço, com a introdução dessas disciplinas. Os exercícios práticos passam a contar com disciplinas que os articulam com a fundamentação teórica.

Mesmo assim, a preocupação com a qualidade dessa formação se aliava muito mais às demandas políticas da época, sempre com vistas à extensão do nível de escolarização da população do que, efetivamente, com a qualidade oferecida.

Cumpre ressaltar que tanto nas escolas de ensino mútuo como na Escola Normal, ou mesmo na formação dos professores adjuntos, personagens que também adquiriram o direito de lecionar, o princípio da aprendizagem da docência se resumiu à observação de outros mestres e à aquisição de modelos. Situação que ganha novos contornos com a propagação das idéias escolanovistas.

\section{Prática de Ensino: para além da observação de modelos}

A segunda década do século XX é marcada pela "preocupação e entusiasmo" pelas questões educacionais, tanto no âmbito nacional como internacional, acompanhadas dos ideários escolanovistas, propagados no País principalmente por Lourenço Filho e Anísio Teixeira, e que visavam à substituição das proposições do ensino intuitivo, que até então tinha servido de base para o trabalho na escola primária e para a formação dos professores.

Em 1920, com o objetivo de atender o maior número de pessoas que não tinham acesso à escola, o ensino primário foi reduzido para dois anos, diminuindo também o tempo de formação dos professores primários. Foi na década de 30 que o currículo da Escola Normal assumiu caráter profissionalizante e a Prática de Ensino foi retirada oficialmente do currículo, sendo substituída por um estágio de vinte horas, que previa 
a regência de aulas em classes de grupos escolares, a ser realizado pelos alunos no quarto ano do curso.

A retirada dessa disciplina do currículo se deve a inúmeras críticas de educadores defensores dos ideários da Escola Nova, em destaque a que se relacionava à concepção de que ensinar resumia-se a uma técnica aprendida pelos futuros professores por meio da observação e reprodução de modelos, o que reforçava a ideia da prática pedagógica ser aprendida sem se levar em consideração o contexto em que ocorria.

Os protagonistas da reforma que ora se instala no País, e que tiveram suas ideias organizadas e propagadas pelo Manifesto dos Pioneiros de 1932, "pretendiam educar o povo pela instrução pública, reformar o ensino e construir uma espécie de 'campo cultural' a partir da universidade” (MAGALDI; GONDRA, 2003, p. 48).

Por isso, acreditavam que a escola deveria ser um "organismo vivo", no qual alunos e professores poderiam, em contato com o ambiente, "possuir, apreciar, sentir a vida" e desenvolver atividades criadoras. Para tanto, esses educadores lutaram para que houvesse integração entre a instituição escolar e o profissional que nela iria atuar.

Dessa maneira, era necessário que a formação de professores oferecesse algo além dos modelos de ensino. Portanto, em 1931 o então diretor-geral da Instrução Pública do Distrito Federal, Anísio Teixeira, põe em prática suas ideias renovadoras, criando o Instituto de Educação e transformando a Escola Normal em Escola de Professores. De acordo com suas ideias, o Instituto de Educação contava com o Jardim de Infância, a Escola Primária e a Escola Secundária, que funcionavam como campo de experimentação, demonstração e prática de ensino para os alunos, futuros professores (SAVIANI, 2007; TANURI, 2000).

Outra mudança diz respeito aos exercícios práticos que, em 1933, retornam ao currículo, agora sob a responsabilidade da disciplina denominada Prática de Ensino, além da introdução de novas disciplinas de formação profissional, como: História da Educação, Sociologia Educacional e Biologia Aplicada à Educação, as quais eram organizadas em seções (ALMEIDA, 1993; TANURI, 2000). 
Pinto (2006, p. 328) esclarece como a Prática de Ensino compunha o currículo do Instituto de Educação: “[...] era considerada o eixo central da formação profissional dos professores, para onde todos os cursos, matérias e atividades das Escolas do Instituto de Educação deveriam convergir [...]", organizando-se em uma estreita articulação entre a Escola de Professores e a Escola Primária.

Assim, além das diversas nomenclaturas que recebeu e das diversas supressões e inclusões que sofreu nos currículos da Escola Normal, a Prática de Ensino, sob os pressupostos escolanovistas, ganha um novo significado. A Escola Nova introduz na formação do professor um novo elemento, além da aprendizagem do método: o aluno como eixo do processo de sua própria aprendizagem, compreendido do ponto de vista biológico e funcional e, nesse sentido, as relações que vão se estabelecendo durante o seu processo de escolarização.

Cabe, então, à Prática de Ensino outra função: um olhar sobre o ensino do ponto de vista da técnica e das relações pedagógicas, respaldado pela ciência. Contudo, mesmo adquirindo um novo significado, a Prática de Ensino ainda era desenvolvida sob a compreensão reduzida de docência, uma atividade restrita à sala de aula, espontânea, já que deveria respeitar as necessidades de cada criança; e, principalmente, que ainda se pautava na ideia de que sua aprendizagem se daria essencialmente pela prática.

Entretanto, o Golpe de 1937 e a Era Vargas compõem um conjunto de acontecimentos que podem nos fazer compreender por que esses ideários, embora tenham significado um avanço, não se fortaleceram. Entre tantas mudanças e retrocessos que causaram, descaracterizar os ideários escolanovistas, por meio da promulgação das Leis Orgânicas do Ensino, foi um deles.

Assim sendo, nessa época tínhamos o Curso Normal Regional, os Institutos de Educação, além das Escolas Normais. Em meio a essa coexistência de modalidades de formação, é instituído, na Faculdade Nacional de Filosofia da Universidade do Brasil, em 1939, o curso de Pedagogia, com a função de formar bacharéis e licenciados para várias áreas, inclusive para o setor pedagógico. Essa faculdade, que objetivou padronizar os 
cursos das demais instituições do País, possuía uma seção de Pedagogia, de Filosofia, de Ciências e de Letras, além de uma sessão especial chamada Didática. Os bacharéis eram formados em três anos e com mais um ano de curso, na seção Didática, seriam formados os licenciados (SILVA, 2006; TANURI, 2000).

Silva (2006, p. 13) relata que uma das inadequações acerca dessa nova proposta é relativa "à separação bacharelado-licenciatura, refletindo a nítida concepção dicotômica que orientava o tratamento de dois componentes do processo pedagógico: o conteúdo e o método".

Em 1950, em São Paulo, o então governador do Estado decreta o Regimento Interno das Escolas Normais Oficiais, o que, entre outras coisas, distribuiu o currículo do ensino normal em quatro seções; deu destaque à Prática de Ensino, ampliando sua carga horária para seis horas/ aulas semanais; e, o mais interessante, instituiu uma prova de Prática de Ensino, em que o aluno deveria executar um plano organizado sobre tema sorteado 24 horas antes do exame, apresentá-lo e depois submeter-se a uma "ligeira arguição" para justificar as escolhas metodológicas utilizadas em sua aula prática (ALMEIDA, 1993).

Sem modificar a ideia de que o curso primário era o lugar por excelência para a Prática de Ensino, esse Regimento também prevê uma integração mais articulada entre os estudos dos métodos e processos e sua aplicação prática e os elementos teóricos e técnicos de outras disciplinas, demonstrando a necessidade de certa articulação entre as áreas.

Contudo, muito longe da crítica conferida à Prática de Ensino pelos pioneiros da educação, na década de 1930, o caráter tecnicista dessa disciplina foi retomado com ênfase, pois, de acordo com Almeida (1993, p. 81), o Regimento Interno das Escolas Normais Oficiais, em seu artigo 73, que tratava sobre as Diretrizes Didáticas, orientava que os princípios técnicos das aulas deveriam ser observados pelos mestres, pois seriam esses os padrões a serem adotados pelos normalistas que observavam essas aulas.

Além disso, em seu artigo 111, continua a autora, o curso primário tinha como finalidade servir de local de "observação, experimentação e prática de métodos e processos de ensino”. 


\section{Estágios curriculares: um apêndice nos cursos de formação inicial}

Almeida (1993) e Tanuri (2000) entendem que a LDB n. 4.024 (BRASIL, 1961) não provocou grandes mudanças estruturais no curso normal. Destacam, entretanto, que os estágios começam a ser realizados fora do horário das aulas de Metodologia e Prática de Ensino, como uma disciplina complementar, com duração mínima de 30 horas por semestre.

Embora essa mudança dê continuidade à referência do caráter prático da docência, o fato de os estágios serem realizados fora do horário de aula descaracterizou o entendimento que se tinha da importância de os normalistas serem acompanhados e orientados pelos professores mestres. Essa determinação foi reafirmada pela LDB n. 5.692/71 (BRASIL, 1971) e ainda vigora na atual LDB, promulgada em 1996.

Nessa conjuntura o curso de Pedagogia, criado em 1939, passa por algumas alterações, por meio de Pareceres emitidos pelo recém-criado Conselho Federal da Educação. Nessa direção, o Parecer CFE n. 252/69, ao reestruturar o currículo do curso, introduz as habilitações técnicas, possibilitando, portanto, que o aluno, em uma dada etapa, pudesse optar pelas disciplinas em função das atividades que pretendesse desempenhar, dentre aquelas já previstas para o pedagogo e aquelas que vinham se delineando. Tendência que, segundo Silva (2006), se intensificava na área da educação em geral: alinhar os currículos às tarefas a serem desenvolvidas em cada profissão.

Visão essa que também foi ratificada pela LDB n. 5.692/71 (BRASIL, 1971), legislação que com o objetivo principal de estender os princípios da "racionalidade, eficiência e produtividade", cumpre seu papel de disseminar em todas as escolas do País a pedagogia tecnicista (SAVIANI, 2007).

Incorporada aos cursos de formação de professores, essa racionalidade técnica concebia o processo de ensino-aprendizagem de forma objetiva e operacional, devendo, tanto o aluno como o professor, se adaptar ao processo de ensino, devidamente planejado pelos técnicos da educação, demarcando, assim, a fragmentação do ensino entre aqueles que o elaboravam, aqueles que o executavam e aqueles que o recebiam. 
Nesse sentido, as Escolas Normais não passaram impunes a essas mudanças que acabaram por descaracterizar sua identidade, que levou mais de um século para se consolidar: seu reconhecimento histórico como um local privilegiado para a formação de professores do ensino primário.

Identificadas como Habilitação Específica para o Magistério (HEM) e seguindo a lógica da "nova" LDB, em relação ao ensino profissionalizante, seu currículo passou a ser organizado por um núcleo comum nacional; uma parte diversificada relacionada à área de cada habilitação profissional e um núcleo de formação especial. Esse último núcleo abrangia as disciplinas de Fundamentos da Educação, Estrutura e Funcionamento do Ensino de $1^{\circ}$ Grau e Didática, incluindo Prática de Ensino.

De acordo com o Parecer CFE n. 349/72 (BRASIL, 1972), cabia à Didática fundamentar a Metodologia do Ensino, do ponto de vista do planejamento, execução e verificação da aprendizagem, conduzindo à Prática de Ensino, que deveria se desenvolver sob a forma de estágio supervisionado. Havia uma indicação nesse Parecer de que a disciplina Metodologia deveria responder às indagações da realidade, a partir dos estágios e, ao mesmo tempo, que a Prática de Ensino deveria respeitar os fundamentos teóricos adquiridos por meio dessa disciplina. Além disso, a Prática de Ensino poderia ser realizada nas próprias escolas da comunidade, em instituições públicas ou particulares, e ser desenvolvida em qualquer época do curso, não sendo necessária sua concomitância com a Didática.

Almeida (1993, p. 129, grifo da autora) nos ajuda a pensar como se instala mais uma contradição na formação de professores:

[...] os "Estágios Supervisionados", pertencentes ao curso como um todo, visando promover a interdisciplinaridade, mas sendo sua supervisão e organização atribuída ao docente responsável por Didática e/ ou Metodologia, acabou por ligar-se exclusivamente a essas disciplinas, descaracterizando a Prática de Ensino como disciplina autônoma, não dando espaço nem se este fosse reivindicado pelos professores dos demais componentes curriculares. 
Nessa perspectiva, as duas Leis de Diretrizes e Bases da Educação que antecederam a que hoje está em vigor provocaram o desmantelamento das Escolas Normais, que vinham se consolidando como espaço exclusivo de formação e que tinham na Prática de Ensino seu principal foco. E, ressaltamos, aprofundou-se a distância entre o campo teórico e prático da formação, permitindo que os estágios supervisionados fossem realizados fora do horário de aula.

O que assistimos hoje, reflexo dessa medida, é o nível de burocratização que o Estágio Supervisionado conseguiu atingir, pois, sendo uma exigência para a certificação, perdeu sua finalidade principal. Além disso, essa medida provocou um distanciamento entre a instituição formadora e as escolas-campo, transformando em exceção aquilo que Caetano de Campos e Anísio Teixeira acreditavam que deveria ser condição sine qua non para a disciplina Prática de Ensino cumprir seu objetivo.

\section{Uma nova conjuntura social e a repetição de velhos modelos}

O processo de democratização por que passou a sociedade brasileira na década de 1980 recuperou muitas ideias que foram fervorosamente debatidas antes do regime militar de 1964, assim como inaugurou novos pensamentos decorrentes de outra compreensão sobre o papel social da escola.

Nesse sentido é que Saviani (2007) nos alerta sobre como a década de 1980 foi um "momento privilegiado para a emersão de propostas pedagógicas contra-hegemônicas", pois essas pedagogias procuravam explicar o fenômeno educativo de outro prisma, levando em consideração seus condicionantes políticos e sociais, sem, no entanto, reduzirem a função social da escola à reprodução da ideologia dominante.

As produções acadêmicas que buscavam na sociologia o seu aporte teórico denunciavam o estado em que se encontravam as escolas públicas do País, pondo em xeque os modelos escolares e situando a formação do professor no contexto sócio-histórico, objetivando destacar os determinantes dessa 
formação e encontrar formas de adequá-la à ideia de que a escola poderia ser um dos espaços promotores da transformação social (TANURI, 2000).

É nesse contexto, combinado com as péssimas condições de formação do professor no País, a queda das matrículas da HEM e o descontentamento com a desvalorização do professor, que surge a proposta referente ao projeto dos Centros de Formação e Aperfeiçoamento do Magistério (CEFAM), elaborado pelo MEC, em 1982, e implantado em 1983 em seis Estados, totalizando, nessa época, 55 Centros (TANURI, 2000).

Dentre tantos aspectos que poderiam ser destacados sobre esse novo formato institucional, elegemos aqueles que se relacionam à carga horária do curso, que passou a ser oferecido em quatro anos, em período integral, além de ampliar a carga horária dos estágios supervisionados de 300 para 360 horas obrigatórias, realizadas a partir do terceiro ano. Para tanto, eram ofertadas bolsas de estudo, inicialmente pelo governo federal e depois pelos próprios Estados, para a garantia do tempo integral e o desenvolvimento dos estágios supervisionados em escolas da comunidade (ALMEIDA, 1993; TANURI, 2000).

Em nosso entendimento, as iniciativas contidas na proposta do CEFAM demarcam uma tentativa de revitalizar o campo de formação de professores. Todavia, o aspecto mais importante a ser ressaltado é a ausência de qualquer alteração qualitativa sobre a Prática de Ensino.

Isso pode ser constatado ao tomarmos como exemplo a versão preliminar, datada de 1994, da Proposta Curricular para o Ensino de Didática/ Prática de Ensino elaborada pela Secretaria de Estado da Educação de São Paulo. Embora a proposta tenha assinalado a necessidade de um Plano de Estágio integrado ao Plano Escolar e ao Plano de Curso e, "se possível, dos professores da escola que recebem estagiários", com a finalidade de envolver todos os professores e a escola "na organização, planejamento, execução e avaliação das atividades práticas dos alunos", ao nos reportarmos às atividades sugeridas, percebemos seu caráter ainda conservador (SÃO PAULO, 1994, p. 57-58).

O documento apresentava proposta, para a disciplina Prática de Ensino e Estágio Supervisionado, dividida em três unidades, a saber:

a) observação e reflexão; 
b) observação participativa, que poderia incluir desde um projeto de elaboração de cartilha, coordenado pelo professor de Didática, até um mural didático, com assuntos de interesse das crianças;

c) a docência supervisionada, cujo objetivo era fazer com que os alunos vivenciassem na prática a atividade docente, "suas dificuldades, seu dinamismo, flexibilidade e, principalmente, sua viabilidade, encaminhando-se por esta via para reflexão sobre seu próprio desenvolvimento enquanto docente, suas dúvidas, sua angústias e por que não, o momento em que vai 'sentir' a profissão" (SÃO PAULO, 1994, p. 64).

Muitos equívocos e contradições podem ser ressaltados no documento. A proposta curricular apresenta, em lugar de diretrizes, sugestões de atividades a serem desenvolvidas pelos alunos e professores, entrando em contradição com o referencial teórico preliminarmente apresentado de forma superficial e difusa. Assim, a prática de ensino continuava sendo concebida como um momento de aplicação de métodos e técnicas, de forma estanque, em uma realidade que se predispusesse a aceitar os estagiários.

Assim, o que se viu até aqui em termos de formação de professores, mais especificamente em relação à Prática de Ensino, mesmo em uma conjuntura favorável às inovações, foi a repetição do que já vinha ocorrendo.

Desse modo, instalam-se no País três instâncias de formação distintas: as Habilitações Específicas para Magistério, com um currículo reduzido; os CEFAMs em tempo integral; e o curso de Pedagogia. E é nesse cenário que a Lei n. 9.394/96 (BRASIL, 1996), a Lei de Diretrizes e Bases da Educação Nacional, é promulgada, estando em vigor até hoje.

\section{A exaltação da prática como campo de aprendizagem da docência}

Nessa parte do artigo, ao indicarmos os desdobramentos da LDB n. 9.394/96, não trataremos com mais profundidade os documentos 
norteadores da formação que antecederam a aprovação das Diretrizes Curriculares Nacionais para o Curso de Pedagogia e que instalaram, ao menos por um curto espaço de tempo, os Institutos Superiores de Educação e seu desdobramento: os Cursos Normais Superiores.

Embora as Diretrizes Curriculares Nacionais para o Curso de Pedagogia, Resolução CNE/CP n. 1/2006, não revoguem a legislação que as cria, seu artigo 11 indica que os Cursos Normais Superiores já autorizados sejam transformados em cursos de Pedagogia, a partir da elaboração de um novo projeto pedagógico. Uma vitória parcial em defesa do curso de Pedagogia como única e principal instância de formação de professores de educação infantil e das séries iniciais do ensino fundamental, fruto da resistência política de educadores que se organizaram e se impuseram diante dos legisladores.

Nessa perspectiva ocorre um movimento gradativo de fechamento dos cursos de formação oferecidos no ensino médio, as antigas HEMs e CEFAMs, fato que instalaria definitivamente a formação de professores no ensino superior.

Muitos seriam, também, os temas a serem analisados no Parecer CNE/CP n. 5/2005 ${ }^{6}$, que trata sobre as Diretrizes Curriculares Nacionais para o Curso de Graduação em Pedagogi, e na Resolução CNE/CP n. 1/2006, que as institui, mas para mantermos o foco deste artigo nos limitaremos a analisar como esses documentos e alguns outros que nortearam a sua elaboração apresentam e concebem a Prática de Ensino e os Estágios Supervisionados.

$O$ fato de o curso de bacharelado em Pedagogia ter se transformado em licenciatura inseriu a docência como eixo principal para a elaboração do seu projeto pedagógico, seguido pelo eixo da gestão educacional e pesquisa. Por esse motivo acreditamos que a Prática de Ensino e os Estágios Supervisionados ganham novos destaques.

A prática a que se refere o documento vai além da ideia que vínhamos até aqui apresentando. O Parecer CNE/CP n. 9/20017 traz

\footnotetext{
${ }^{6}$ Esse Parecer foi reexaminado pelo Parecer CNE/CP n. 3/2006.

7 Documento que indica as Diretrizes Curriculares para a Formação de Professores da Educação Básica e que subsidiou a elaboração das diretrizes do curso de Pedagogia.
} 
uma concepção de prática mais como componente curricular", o que implica em compreendê-la como "uma dimensão do conhecimento que tanto está presente nos cursos de formação, nos momentos em se que trabalha na reflexão sobre a atividade profissional, como durante o estágio, nos momentos em que se exercita a atividade profissional (BRASIL, 2001, p. 23).

Alguns estudos (CAMPOS, 2006; KUENZER; RODRIGUES, 2007) apontam o quanto esse Parecer CNE/CP n. 9/2001, promove, em seu conteúdo, aquilo que os autores chamam de "epistemologia da prática”. Objetivando transcender um modelo de formação que carregou, durante mais de um século, a racionalidade técnica, o documento indica a necessidade de desenvolver competências no futuro professor para que este saiba resolver as questões que surgem no cotidiano escolar, justamente porque as realidades são diversas e únicas e, portanto, esse professor deve estar preparado para a imprevisibilidade do processo de ensino-aprendizagem.

Nesse sentido, é necessário que esse professor seja mais envolvido em situações práticas, para que essa vivência possibilite a seleção de suas estratégias de ação de forma criativa, por meio de um arcabouço teórico adquirido antes e durante a própria prática.

Nessa direção, em relação aos estágios supervisionados, o Parecer CNE/CP n. 5/2005 (BRASIL, 2005), que trata sobre as diretrizes do curso de Pedagogia, assevera que:

o estágio curricular pressupõe atividades pedagógicas efetivadas em um ambiente institucional de trabalho, reconhecido por um sistema de ensino que se concretiza na relação interinstitucional, estabelecida entre um docente experiente e o aluno estagiário, com a mediação de um professor supervisor acadêmico. Deve proporcionar ao estagiário uma reflexão contextualizada, conferindo-lhe condições para que se forme como autor de sua prática, por meio da vivência institucional sistemática, intencional, norteada pelo projeto pedagógico da instituição formadora e da unidade campo de estágio. 
Se analisarmos bem a legislação, encontramos um discurso que quase nos convence do ponto de vista das ideias, mas não explica com profundidade quais são as indicações possíveis para que ele se realize.

Ressaltamos isso porque, ao apresentarmos como a Prática de Ensino e os Estágios Supervisionados foram sendo concebidos e tratados, ao longo da história, ora no discurso da lei, ora nas ações desenvolvidas, objetivando a sua implementação, percebemos como esses componentes da formação inicial foram se distanciando e, como consequência, seus objetivos relacionados à aprendizagem da docência foram se diluindo.

Dessa forma, asseverar que a aprendizagem da docência deve se desenvolver sob a responsabilidade da instituição formadora, do próprio aluno e da escola-campo, sem o respaldo político necessário para essa efetivação, significa desconsiderar, no mínimo, todas as dificuldades históricas e políticas pelas quais passaram as instâncias de formação de professores.

Além disso, e para nós o mais instigante, é que mais uma vez os princípios norteadores dessa discussão sobre prática e estágio não rompem com as duas racionalidades - técnica e prática - que nortearam as práticas de formação docente expostas até aqui neste texto.

Tomando como base essa assertiva, Campos (2006, p. 112) nos ajuda a reconhecer o desafio que ainda temos pela frente como formadores. A autora, ao questionar alguns professores de cursos de licenciatura sobre seu entendimento a respeito da compreensão da expressão "prática como componente curricular", constata que:

[...] diante da maioria das manifestações dos docentes sobre as propostas de reestruturação dos currículos nos cinco cursos de licenciatura pesquisados, levando em conta os indicadores de prática como componente curricular e estágio supervisionado, nota-se uma dificuldade na adoção e entendimento do que vem a ser tal prática, confundindo e delimitando-a, geralmente, à ação do ensino nas escolas.

Em relação ao estágio, a autora afirma: “[...] é ainda concebido como [...] momento de constatação de uma realidade, como uma prática no sentido restrito à experiência" (CAMPOS, 2006, p. 114). 
Esses professores não estão adotando a mesma perspectiva da legislação; pelo contrário, não conseguiram romper com a visão tradicional de aplicabilidade da teoria, entendendo a prática de ensino como local para organizar aquilo que vai ser colocado em prática nos estágios supervisionados. Parece-nos que, de acordo com essas afirmações, para esses professores, Prática como componente curricular, Prática de Ensino e Estágio são a mesma coisa.

Longe de desejar desviar a problemática da questão, culpando os professores, nosso objetivo é assinalar o quanto esses dois componentes da formação necessitam ser melhores interpretados, à luz da legislação e da literatura existente sobre formação, para que tenhamos um campo de conhecimento que facilite nossa compreensão sobre o impacto da Prática de Ensino e dos Estágios Supervisionados na aprendizagem da docência.

\section{Considerações finais}

Este artigo procurou mostrar os descaminhos das Práticas de Ensino e dos Estágios Supervisionados alinhados ao desenvolvimento das políticas brasileiras de formação inicial de professores. Os contornos dessa formação foram se dando por meio de diversas concepções políticas e pedagógicas sobre formação, função da escola primária, natureza do ofício docente e qualidade da educação, legitimados, nos diversos contextos históricos, pela legislação vigente.

Dessa forma, pudemos verificar que somos herdeiros de uma formação inicial de professores pautada nos pressupostos da racionalidade técnica, que percorreu a história da educação brasileira, desde o surgimento da primeira Escola Normal, ganhando mais força pela LDB n. 5.692/71.

Essa herança convive hoje com outro pressuposto de formação, a racionalidade prática, posta em evidência na década de 1990, tanto pela universidade, por meio de estudos e pesquisas sobre a formação de professores, como pela legislação, principalmente a partir da homologação do Parecer CNE/CP n. 9/2001, que instituiu as Diretrizes Curriculares para a Formação 
de Professores da Educação Básica, e pela Resolução CNE/CP n. 1/2006, que instituiu as Diretrizes Curriculares para os Cursos de Pedagogia.

Por se tratar de um legado validado pela legislação, a força de seus pressupostos se faz presente nos currículos atuais de formação inicial de professores e aparece com mais ênfase em disciplinas como Didática, Prática de Ensino (ou nomes correlatos) e nos Projetos de Estágios Supervisionados.

Resta-nos, então, tomando como base a constatação anterior, encontrar na história e nas práticas cotidianas de formação componentes que poderão nos auxiliar na ruptura dessas lógicas - técnica e prática para caminharmos na direção de um modelo crítico de formação.

Ao compreender a educação, em sua totalidade, esse último modelo exige que a formação inicial de professores desenvolva nos alunos a possibilidade de compreensão do fenômeno educativo nessa perspectiva, para que, a partir disso, percebam quais condicionantes dessa realidade incidem em sua prática pedagógica e quais as possibilidades do seu trabalho, uma atividade social, tornar-se definitivo no processo de emancipação do outro.

Para tanto, não podemos nos limitar a desenvolver formas de reflexão sobre os conhecimentos que são próprios da prática pedagógica, mas nutrir aprendizagens que possam originar conhecimentos - de natureza teórico-prática - que possibilitem uma análise crítica sobre como se estrutura a realidade na qual a docência se desenvolve.

Um processo de formação inicial pautado por esse princípio deve desenvolver no aluno um exercício de reflexão que alcance a compreensão sobre a cultura institucional em que trabalha e como ela interfere na ação de cada um dos participantes, além de ajudá-lo a desvelar qual o referencial político e epistemológico que conduz sua prática, que motivos o levam a escolher esse referencial, podendo, assim, optar pelo sentido social que deseja imputar à sua ação.

A formação inicial pode, assim, representar um tempo de formação em que podemos combater o modelo de profissional de educação assistencialista e alienado, proporcionando a possibilidade de o professor perceber a dimensão política e cultural de seu ofício, oferecendo-lhe recursos para desenvolver sua profissionalização. 


\section{Referências}

ALMEIDA, J. S. A escola normal paulista: estudo dos currículos (1846 a 1990) Destaque para a Prática de Ensino. Boletim do Departamento de Didática, Araraquara, ano XI, n. 9, 1993.

BRASIL. Lei n. 4.024, de 20 de dezembro de 1961. Fixa as diretrizes e bases da educação nacional. Diário Oficial [da] República Federativa do Brasil, Poder Legislativo, Brasília, DF, 27 dez. 1961. p. 11429. Disponível em: <http://www. planalto.gov.br/ccivil_03/Leis/L4024.htm>. Acesso em: 20 jul. 2010.

BRASIL. Lei n. 5.692, de 11 de agosto de 1971. Fixa diretrizes e bases para o ensino de primeiro e segundo graus, e da outras providencias. Diário Oficial [da] República Federativa do Brasil, Poder Legislativo, Brasília, DF, 12 ago. 1971. p. 6377. Disponível em: < http://www6.senado.gov.br/legislacao/ ListaTextoIntegral.action?id=75576>. Acesso em: 23 maio. 2009.

BRASIL. Parecer CFE n. 349/72, 6 de abril 1972. Exercício do magistério em $1^{\circ}$ grau, habilitação específica de $2^{\circ}$ grau. Disponível em: <http://lise.edunet. sp.gov.br/paglei/notas/parcfe349_72.htm>. Acesso em: 8 jul. 2008.

BRASIL. Lei n. 9.394/96, de 20 de dezembro de 1996. Estabelece as diretrizes e bases da educação nacional. Diário Oficial [da] República Federativa do Brasil, Poder Legislativo, Brasília, DF, 23 dez. 1996. p. 27833. Disponível em: <http://www6.senado.gov.br/legislacao/ListaTextoIntegral.action?id=75723 >. Acesso em: 23 maio 2009.

BRASIL. Ministério de Educação e do Desporto. Conselho Nacional de Educação/ Conselho Pleno. CNE/CP n. 9/2001, de 8 de maio de 2001, Diretrizes Curriculares Nacionais para a Formação de Professores da Educação Básica, em nível superior, licenciatura, graduação plena. Brasília, DF, 8 maio 2001. Disponível em: 〈http://portal.mec.gov.br/cne/arquivos/pdf/009.pdf〉. Acesso em: 15 jul. 2009. 
BRASIL. Ministério de Educação e do Desporto. Conselho Nacional de Educação/ Conselho Pleno. Parecer CNE/CP n. 5/2005, de 13 de dezembro de 2005. Diretrizes curriculares nacionais para o curso de pedagogia. Brasília, DF, 13 dez. 2005. Disponível em: <http://portal.mec.gov.br/cne/arquivos/pdf/pcp05_05. pdf $>$. Acesso em: 17 jul. 2009.

BRASIL. Resolução CNE/CP n. 1/2006, 15 de maio de 2006. Institui diretrizes curriculares para o curso de graduação em pedagogia, licenciatura. Disponível em: 〈http://portal.mec.gov.br/cne/arquivos/pdf/rcp01_06.pdf〉. Acesso em: 15 jul. 2009.

CAMPOS, M. Z. de. A prática nos cursos de licenciatura: reestruturação curricular da formação inicial. 2006. 171 f. Tese (Doutorado em Educação) - Pontifícia Universidade Católica de São Paulo, São Paulo, 2006.

KUENZER, A. Z.; RODRIGUES, M. de F. As diretrizes curriculares para o curso de pedagogia: uma expressão da epistemologia da prática. Olhar do professor, Ponta Grossa, v. 10, n. 1, p. 35-62, 2007. Disponível em: <http://www.revistas2. uepg.br/index.php/olhardeprofessor/issue/view/143/showToc>. Acesso em: 23 maio 2008.

MAGALDI, A. M.; GONDRA, J. G. A reorganização do campo educacional no Brasil: manifestações, manifestos e manifestantes. Rio de Janeiro: 7 Letras, 2003.

PINTO, K. P. Por uma nova cultura pedagógica: prática de ensino como eixo da formação de professores primários do Instituto de Educação do Rio de Janeiro (1932-1937). 2006. 390 f. Tese (Doutorado em Educação) - Programa de pós-graduação em educação: história, política, sociedade da Pontifícia Universidade Católica de São Paulo, São Paulo, 2006.

SÃO PAULO. Secretaria de Estado da Educação - SEE. Coordenadoria de Estudos e Normas Pedagógicas - CENP. Proposta Curricular para o Ensino de Didática/ Prática de Ensino e Estágio. Versão para estudo. São Paulo: SEE, 1994.

SAVIANI, D. História das idéias pedagógicas no Brasil. Campinas: Autores Associados, 2007. 
SILVA, C. S. B. Curso de pedagogia no Brasil: história e identidade. 3. ed. Campinas: Autores Associados, 2006.

TANURI, L. M. História da formação de professores. Revista Brasileira de Educação, n. 14, p. 61-88, 2000.

TARDIF, M. Saberes docentes e formação profissional. Petrópolis: Vozes, 2002.

Recebido: 31/05/2011

Received: 05/31/2011

Aprovado: 21/06/2011 Approved: 06/21/2011 